\title{
The quality of the environment in the Rosia of Jiu quarry as a result of the use of Caterpillar 323D $L$ and 323D LN excavators
}

\author{
Bogdan Ioan Marc ${ }^{1 *}$, Alexandra Stanimiresu Soica ${ }^{2}$, and Sorin Mihai Radu ${ }^{3}$ \\ ${ }^{1}$ University of Petrosani, Department of Mechanical, Industrial and Transport Engineering, \\ University Street 20, Petrosani, Romania \\ ${ }^{2}$ University of Petrosani, Department of Mechanical, Industrial and Transport Engineering, \\ University Street 20, Petrosani, Romania \\ ${ }^{3}$ University of Petrosani, Department of Mechanical, Industrial and Transport Engineering, \\ University Street 20, Petrosani, Romania
}

\begin{abstract}
This paper studies how the activity of hydraulic excavators found in the Rosia quarry of Jiu affects the environment. For this study we chose the Caterpillar 323D L and 323 D LN hydraulic excavators. The study took place over a period of 30 days. These days we have collected data on the noise level and the level of PM 10 particles in the quarry. Caterpillar equipment not only helps to build a better world, but also helps to preserve the environment, which is so fragile today. The evolution of excavators has led to a more efficient way of working both in terms of production, costs and effects on the environment. Their efficient way of working has led to an increase in production and a decrease in the level of pollution in the Rosia Quarry area.
\end{abstract}

\section{Introduction}

In 1973, between the villages of Zatreana and Mosneni, the activity of the Rosia quarry begins. It is considered the largest mining quarry in Europe, but also the one with the largest excavators in Europe. Although it is the largest quarry in Europe, the coal extracted is of inferior quality and is used as fuel in thermal power plants.

Coal extraction in the Roșia quarry is carried out in steps with a height of approximately 15 meters and a width of 12 meters, up to a depth of 360 meters. The extracted coal is loaded with excavators in dump trucks and is directed so that the tailings reach the coal dumps and the ore is transported to the crusher to be crushed. After crushing, the ore is transported to the preparation plant. The coal extracted in the Roșia quarry is Lignite. This is a natural coal, but of a lower quality, which has a brown color and is very crumbly. It is used as fuel in thermal power plants [1].

This paper studies the working of hydraulic excavators found in the Rosia quarry and how their activity affects the environment.

\footnotetext{
${ }^{*}$ Corresponding author: bogdanmarc94@yahoo.com
} 


\section{Working methods and results}

For this paper we chose the 323D L and $323 \mathrm{D}$ LN hydraulic excavators. These were observed over a period of 30 days, during which time we collected data on PM $10 \mu \mathrm{m}$ particles resulting from their drilling activity, and data on noise levels. The PM $10 \mu \mathrm{m}$ suspended particles were measured using the HPM32322550 sensor which uses laser-based light scattering to detect both $2.5 \mu \mathrm{m}$ and $10 \mu \mathrm{m}$ particles. Noise level was measured using a Noise Level Sensor sample [2-4].

The D-Series hydraulic excavators are very easy to operate, have an impressive lifting capacity and use fuel efficiently, thus reducing operating costs. The excavator engine $\mathrm{D}$ is a Cat C6.4 model (Figure 1) that ensures a very high working power and an efficient way of using fuel. The engine operates in two different modes, high power and standard mode. The high power mode is recommended for extremely productive areas and for applications on rough terrain. The par power mode manages the fuel supply to get the best performance per liter of fuel. The engine power management system ensures flexible fuel dosing, allowing the engine to respond quickly to application needs.

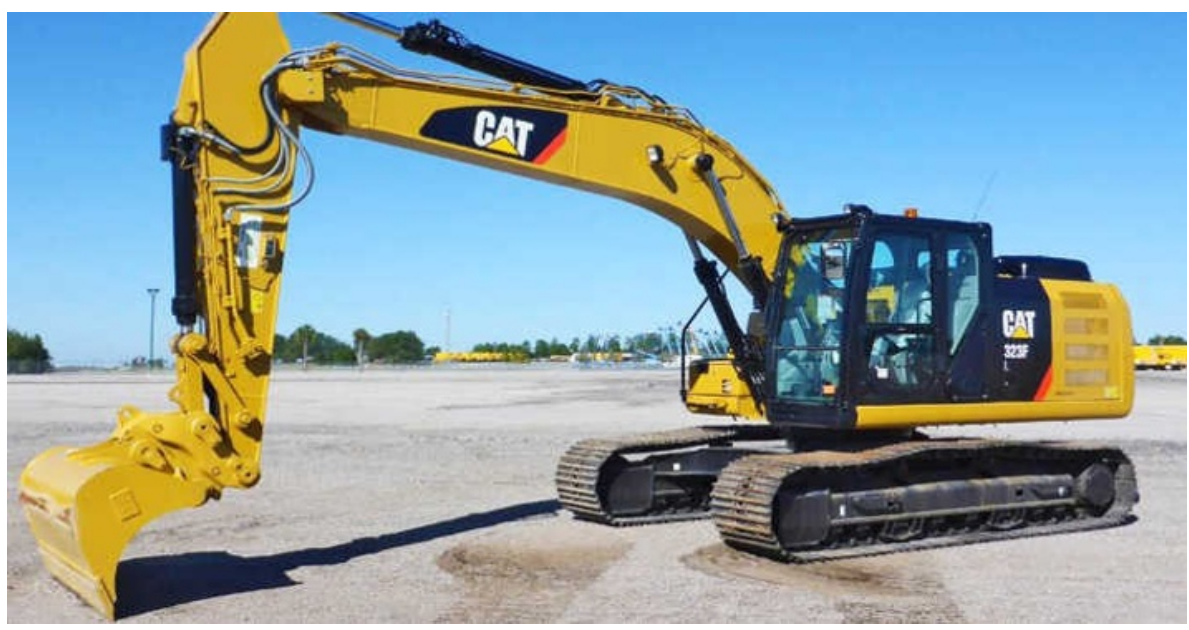

Fig. 1. 323D hydraulic excavator [5].

The Cat C6.4 engine is equipped with electronic controls that drive the mechanically controlled injection system. Multi-point injection of fuel allows a high level of accuracy to be achieved. Precise modeling of the combustion cycle reduces combustion chamber temperatures, generating lower emissions and optimizing fuel consumption. This leads to a higher volume of work in relation to fuel costs. As for the cooling system, in order to reduce the fan noise, the cooling fan is driven by a viscous liquid coupling, which is electrically controlled by the machine control module. It calculates the optimum fan speed based on the engine target speed, coolant temperature, hydraulic oil temperature and actual fan speed at a given time. The Cat C6.4 engine (Figure 2) embodies a new presentation concept that separates the cooling system from the engine compartment. The radial lining air filter has a double layered filter body to achieve more efficient filtration, being placed in a compartment behind the cab. When dust accumulates above a certain limit, a warning is displayed on the monitor. 


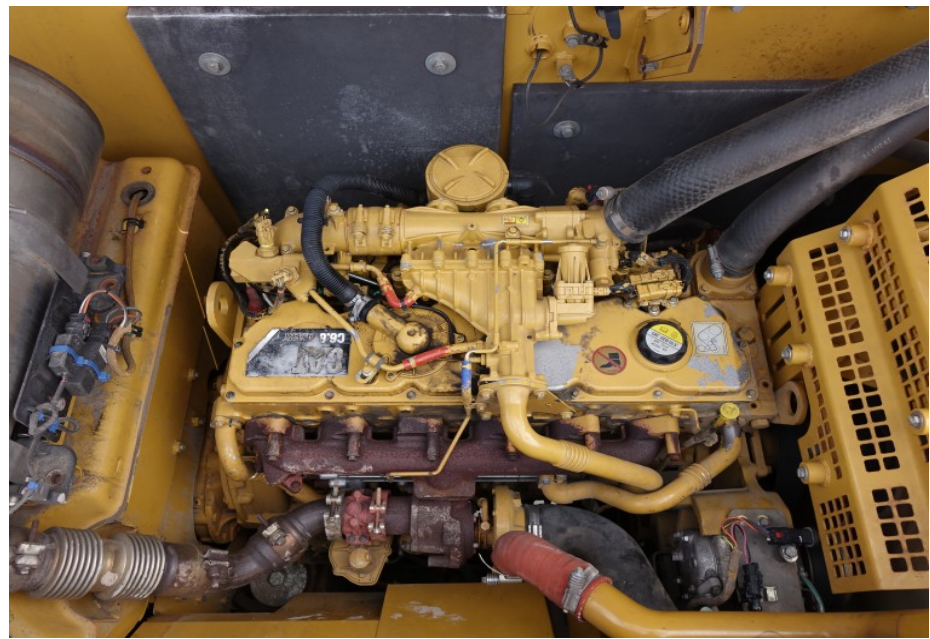

Fig. 2. Cat C6.4 engine [6].

Caterpillar equipment not only helps to build a better world, but also helps to preserve the environment, which is so fragile today. The Cat C6.4 engine integrates a number of improvements by offering a new technology in the field of engines. The technology capitalizes on the three main engine systems: fuel, air and electronics. Engine oil filters and capsule-type hydraulic oil filters are placed vertically and are easily accessible to minimize fluid leakage. Service intervals are extended to reduce the number of fluid exchanges and manipulations. The service interval for the hydraulic oil can be extended to 4000 hours with the SOS program.

The samples for this work were performed in a period of 30 days at intervals of 4 hours per day, obtaining the results presented in the graphs below (Figures 3 - 4). When performing the measurements, all the norms and laws in force were taken into account, the measurements being performed in accordance with Law no. $104 / 15.06 .2011$, the ISO 14001: 2015 standard and GD.493 / 12.04.2006.

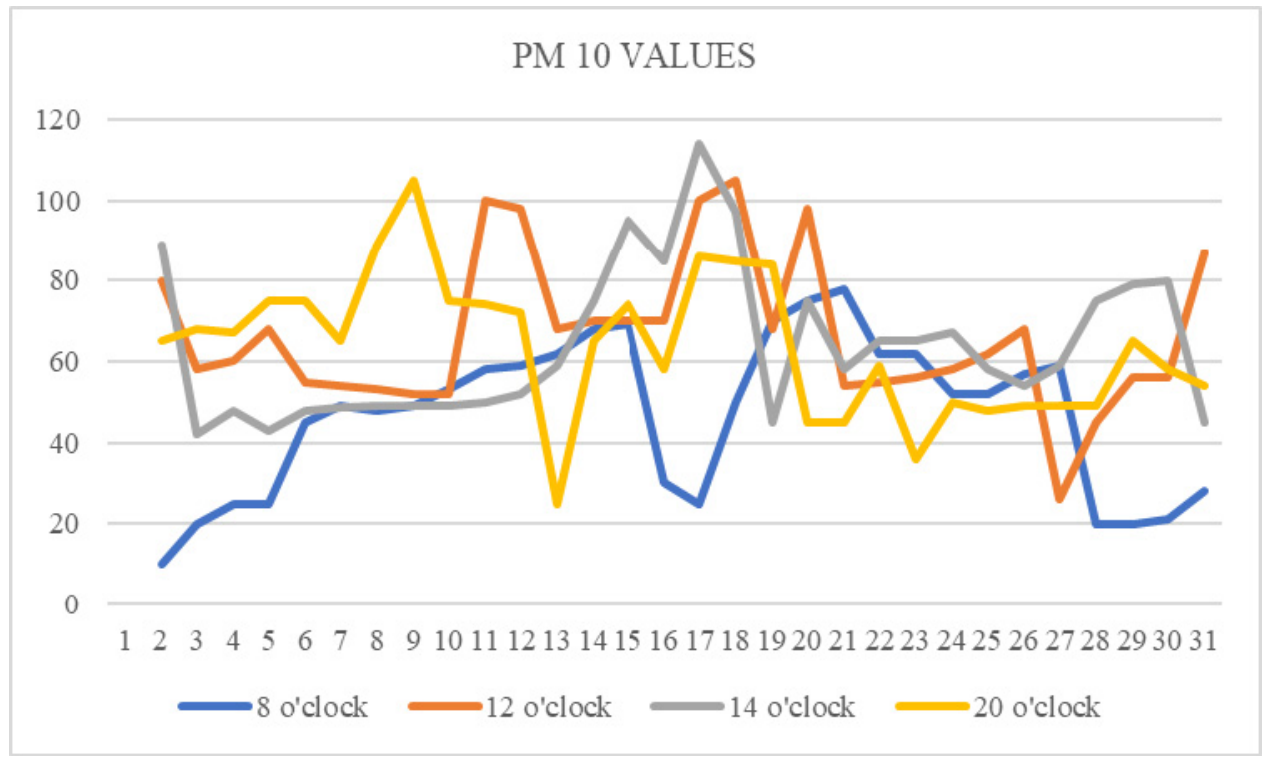

Fig. 3. Variation of PM10 values. 
In the graph above you can see a decrease in the values of PM 10 particles, due to the use of CATERPILLAR 323D L excavators. The measurements were made at 8:00 o'clock; 12:00 o'clock to 14:00 o'clock and 20:00 o'clock and even if we had certain periods of the day with values exceeding 50 units and reaching up to 98 units, we can say that their number is considerably smaller than other periods. The lowest values were recorded at 8 o'clock when we had values of $15 \mathrm{ug}$, but also at 8 o'clock when we had values of $20 \mathrm{ug}$.

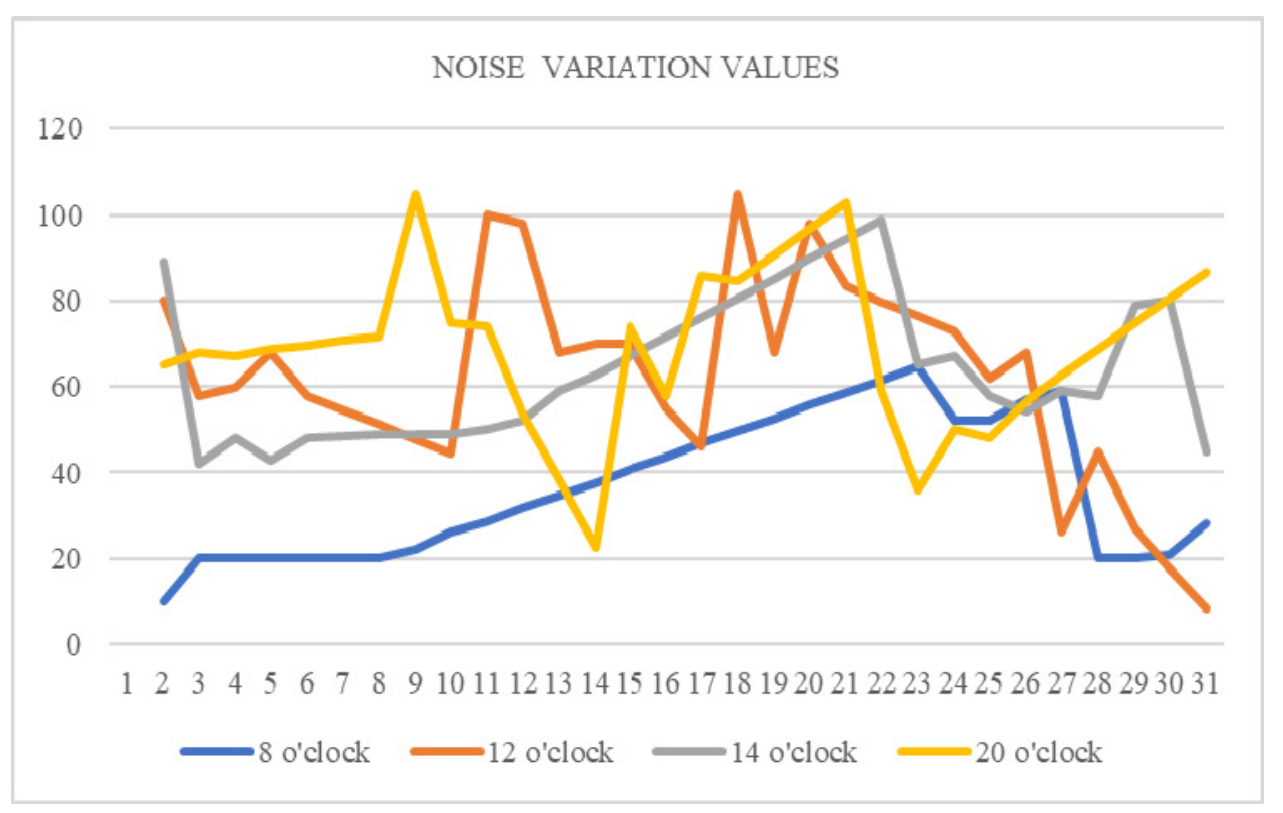

Fig. 4. Variation of noise level values.

The graph above shows the variation in the noise level produced by Caterpillar excavator engines. According to the rules and laws in force, the noise limit values, which must not be exceeded, mainly refer to a daily or weekly exposure of 87 decibels (dB), taking into account any attenuation due to hearing protection. Exposure values that an employer must comply with - are set at a daily or weekly exposure between $80 \mathrm{~dB}$ (lower value) and $85 \mathrm{~dB}$ (upper value) [7].

As we can see during the 30 days the noise level values are very different and vary depending on the time. If at 8 o'clock in the morning we have values from 15 decibels to about 65 decibels, at 12 o'clock we have values that start from about 80 decibels and can reach up to about 100 decibels but also 40 decibels. 14 o'clock brings values that vary between about 80 and 45 decibels, and 20 o'clock records values that vary between 65 decibels and 15 decibels.

\section{Conclusions}

The evolution of excavators has led to a more efficient way of working both in terms of production, costs and effects on the environment. Their efficient way of working has led to an increase in production and a decrease in the level of pollution in the Rosia Quarry area.

Mining activity includes the extraction, transport, storage of coal and its transformation into energy. These activities are responsible for polluting the environment with nitrogen, suspended dust, soot and carbon dioxide, significant increases in noise levels especially in 
the surrounding areas where coal deposits are usually found. All this, once released into the environment, affects both human health and the environment.

Following the analyzes performed, we can say that the environment in the Rosia Quarry area is an environment in which the level of soil pollution and the level of noise pollution is decreasing but not low enough to be able to frame the clean environment.

\section{References}

1. F.F. Șoica, A. Egri, A. Stanimirescu, Analysis of quality indicators from slurry decanters (Annals of the University of Petrosani Mechanical Engineering, 2018)

2. A. Stanimirescu, A. Egri, F.F.Soica, S.M.Radu, Measuring the change of air temperature with 8 LM75A sensors in mining area (MATEC Web of Conferences, 2020)

3. M.S. Morar, S.M. Radu, C. Lupu, D. Cioclea, I. Gherghe, Env. Eng. and Manag. J. 16 (6), 14091414 (2017)

4. F.D. Popescu, S.M. Radu, K. Kotwica, A. Andraş, I. Kertesz, S. Dinescu, Vibration Analysis of A Bucket Wheel Excavator Boom Using Rayleigh's Damping Model, New Trends in Production Engineering 2 (1), 233-241 (2019)

5. Hydraulic excavators User Guide. Available on https://www.bm-cat.com/roro/utilaje/excavatoare-de-talie-medie/323

6. Hydraulic excavators User Guide. Available on http://ibb-hib.ro/wpcontent/uploads/2018/Utilaje/specificatii-tehnice-excavator-senile.pdf

7. Air Quality Avaible on https://www.calitateaer.ro/ 